\title{
SPONTANEOUS FRACTURE IN THERMALLY STRENGTHENED GLASS - A REVIEW AND OUTLOOK
}

\author{
STEFAN KARLSSON \\ RISE Research Institutes of Sweden, Division Built Environment, Glass Section, SE-351 96 Växjö, Sweden \\ "E-mail: Stefan.Karlsson@ri.se
}

Submitted January 23, 2017; accepted March 10, 2017

\begin{abstract}
Keywords: Strengthened glass, Spontaneous Fracture, Nickel sulphide inclusions
Thermal strengthening of glass is common for many different purposes including architecture, automotive, glasses for solar energy, tableware and occasionally also containers. It is an easy and relatively cheap method to make glasses stronger, however, with an Achilles heel that it can spontaneously fracture without the slightest applied external force. Though, fracture due to applied external force is the most common case, spontaneous fracture is rare. The current paper reviews the literature of spontaneous fracture and NiS inclusions and what kind of mitigation measures that have been done in order to reduce the frequency of spontaneous fracture. Finally is also an outlook for the alternative mitigation measures and their advantages as well as disadvantages. A personal perspective is given in discussions and gives an outlook to the most promising alternative methods to reduce and hopefully eliminate the NiS inclusions. These include multi-functional methods where not only the NiS inclusion issue is solved.
\end{abstract}

\section{INTRODUCTION}

Thermally strengthened glass [1-3], also frequently called tempered, hardened or toughened glass. The principle of thermal strengthening is based upon the fact that glass is more fragile in tension than in compression and uses, in a phenomenal way, the physical and fundamental properties of glass by rapidly cooling the glass uniformly. The glass is commonly quenched with pressurized air and the glass surface cool more rapidly so that instantaneously will the surface contract more than the interior. As the glass surface reaches the glass transformation temperature $\left(T_{g}\right)$, it will become an elastic solid contracting less rapidly than the viscoelastic interior that can still undergo relaxation. The contractionmismatch during rapid cooling build up compressive stresses in the glass surface and tensile stresses in the interior, see Figure 1. The surface compressive stresses are approximately two times the values of the central stresses if assuming that the residual stress profile is truly parabolic. Depending on the quench rate will high central tensile stresses be built up in the interior and these will influence the fracture behavior of the glass, see Figure 1, a term called frangibility [4-6]. The high strain energy in the thermally strengthened glass will be released in creating new surfaces, i.e. creating small blunt glass fragments, but energy will also be released as sound, heat generation and kinetic energy (accelerating the fragments) $[2,3,5]$. Thermal strengthening of glass has been reviewed extensively by several authors over the years [1-3, 7-9] and the first case of thermal strengthening is the so-called Prince Rupert's drop that the well-known Hooke observed in 1665 [10, 11], a phenomenon which still receives scientific attention [1214]. The fact that thermally strengthened glass fracture into small blunt pieces [15] has the advantage that it is less dangerous and there is a standard for "fully" thermally strengthened glass or frequently called "safety" glass EN $12150[2,3]$. The frangibility (number of glass fragments per unit area) can be correlated to the central tensile level to the power of four [5] or the compressive stress [16, 17] and the higher degree of strengthening the more "explosive" may the fracture be experienced.

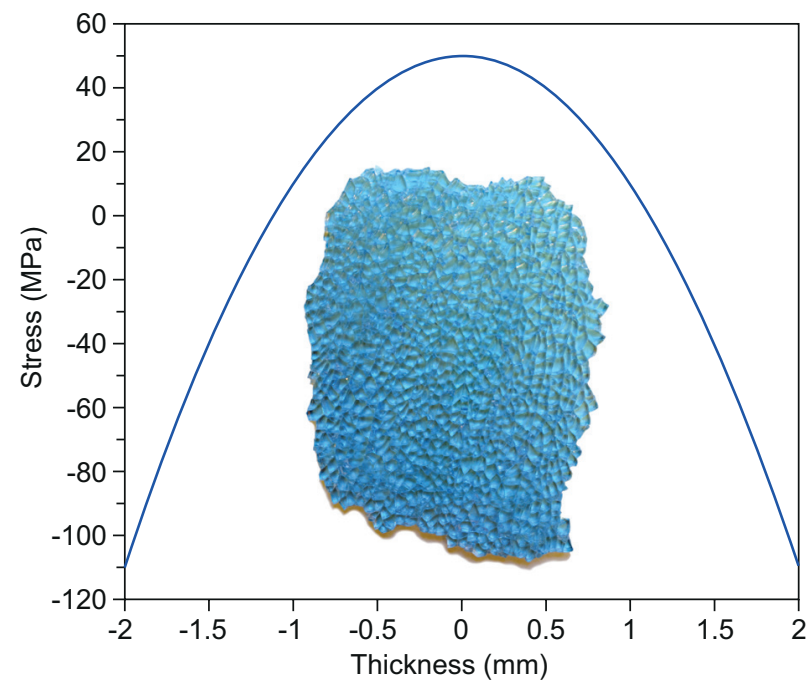

Figure 1. The graph shows a principal parabolic stress profile in thermally strengthened glass. The inset shows a characteristically fragmented thermally strengthened glass. 
With sufficient externally applied forces can thermally strengthened glass fracture due to [18]:

- impacts or bumps,

- thermal load,

- static fatigue (stress-corrosion) [19-21],

especially if the glass surface has been or is being scratched by sharp and hard objects creating surface defects that acts as stress-concentrators, frequently called Griffith flaws as Griffith [22] was a pioneer to mathematically describe stress-concentration of elliptical flaws in brittle solids (glass fibers). The quality of the glass edge is important; a smooth and polished edge reduces the risk for stress concentrations that can make the glass fracture upon applied forces. Flat glass that is to be thermally strengthened must have a processed edge to avoid the risk of fracture in the strengthening-furnace. In order to minimize the risk for breakage, there is also a responsibility on the supplier that installs thermally strengthened glasses in products. Generally shall the glass be mounted so that the edges are protected, high temperature gradients should be avoided, the mounting does not cause tension and the glass is not in contact with hard or sharp materials etc.. Quality assurance of thermally strengthened glass in buildings is made via EN 12150 standard and EN 1863 which is the lower degree of thermally strengthened glass normally called heatstrengthened glass [23]. The standards stipulate that the thermally strengthened glasses fulfill the requirements of dimensional tolerances, deformation tolerances, strength, frangibility, edge treatment and optical distortion etc. Thermally strengthened glass must be marked that they fulfill the standard. Fire glazing are also in some cases thermally strengthened and are assured according to EN 1363-1 and EN 13501-2 where two relevant levels are issued E30 or E60 (30 or 60 minutes that the glass withstands fire) [24].

Defects or inclusions in the glass can also significantly lower the strength of glass in a similar way as Griffith flaws and this can be an effect from the manufacturing [25]. There are around fifty different types of inclusions that have been identified and most of them are harmless [26]. The most common cause of fracture of thermally strengthened glass is due to external influence such as those ascribed above [27]. There are though inclusions that may cause spontaneous fracture of glass without externally applied forces, a phenomenon that has been known since the 1960s [28] or possibly even as early as the 1940s [29]. The pioneering study of Ballantyne [28] correctly identified NiS inclusions to be the cause of spontaneous fracture. The Ni-S phase diagram that can be found in these references: [30-34] show several different stoichiometric crystalline entities and also most importantly high temperature and low temperature-phase frequently denoted $\alpha$ and $\beta$-phase respectively. The cause of the spontaneous fracture is a volumetric expansion as the NiS inclusion undergoes a phase transformation $[35,36]$ and this becomes a problem as thermally strengthened glass is rapidly quenched which gives insufficient time for phase transformation. Recently it has also been suggested that spontaneous fracture can be caused by monolithic silicon particles as well [37], the same authors [38] employs Finite Element Method (FEM) to calculate thermal stresses inflicted by inclusions in glass. It shall be noted that the study do not consider the volume expansion of NiS inclusions as a result of phase transformation but only the effect of the thermal expansion coefficient mismatch, it was concluded that particles less than $0.2 \mathrm{~mm}$ give a low risk of spontaneous fracture but that the duration of the load matters. In the current paper are all the aspects of NiS inclusions reviewed - the origin, the properties, the spontaneous fracture delay and frequency and preventive measures such as the heat soak test (HST) and other alternatives as well as some personal reflections as an outlook how to remedy the problem of NiS inclusions.

\section{THEORETICAL}

\section{Origin of nickel sulfide}

The Nickel source to NiS inclusions is despite how long the problem has been known not clear but probably it is due to contaminations of raw materials such as feeders made of stainless steel or stainless steel materials that are used during storage or handling the raw materials [39]. But other sources, such as thermocouple alloys, burner, corrosion of refractories [40] and the fuel used for heating up the oven, cannot be ruled out. Nickel oxide is also used as a colorant in greyish solar protective glazing's but NSG Pilkington [41] claims that since it is not introduced in its metallic form it is not considered to cause NiS-inclusions. Barry och Ford discusses the possibility that a $\mathrm{Ni}$ source could be $\mathrm{NiO}$ [42] and in the literature there are no studies that $\mathrm{NiO}$ is not a source but it is more likely a conception from the industry based on experience and statistics of greyish colored solar protective glazing's. The flat glass industry has continuously improved its process to reduce the risks and the amounts for contaminations of Nickel. Mitigating measures are for example avoiding contact between raw materials and nickel containing alloys (certain stainless steels) and fire the tank furnaces with natural gas instead of oil that may contain up to three ppm $\mathrm{NiO}[39,43]$. The amount, three ppm, might be seen as insignificant but it can cause NiS inclusions in every second millimeter in the float process. Only $1 \mathrm{~g}$ of Nickel that has reacted with Sulphur and formed NiS can potentially contaminate the float process with NiS inclusions for up to 10 days (corresponding to approximately 6000 tons of glass) [39]. Furthermore, $1 \mathrm{~g}$ of NiS can form up to 1000 inclusions of $0.15 \mathrm{~mm}$ in diameter [44]. Despite all mitigating measures that, primarily, the flat glass industry has made, NiS inclusions still occur [39]. The generally accepted 
origin of Nickel is that it comes from some kind of alloy and that $\mathrm{NiS}$ inclusions are formed in three steps (i) $\mathrm{Ni}$ is separated from the other metals in the alloy according to Ostwald's step theory which depends on the nobility of the metals $[39,45]$, (ii) Ni bonds to Sulphur and forms $\mathrm{NiS}$ according to the chemical equilibria

$$
4 \mathrm{Ni}^{2+}+\mathrm{SO}_{3} \rightarrow \mathrm{NiS}+3 \mathrm{NiO}
$$

and (iii) it is trapped into the glass while the glass is cooled [42]. The NiS inclusions are often spherical but are sometimes elliptical or even cigar shaped [46, 47]. This indicates that the NiS inclusions have been molten but not dissolved into the glass melt floating around like drops of oil in water [48]. The surface of the NiS inclusions is often uneven, like a golf ball, which indicates that it has crystallized during the cooling process. At approximately the $2^{\text {nd }}$ Millennium shift it was reported that the amounts of $\mathrm{NiS}$ inclusions had dropped to a twentieth to what is has been previously but still the flat glass manufacturers cannot guarantee that the glass is free of NiS inclusions [39]. It is not only the flat glass industry that have had problems, also studies of container glass compositions have been made [49]. The Sulphur originates most likely from the fining agent $\mathrm{Na}_{2} \mathrm{SO}_{4}$, which is used in the float process or possibly from the fuel [42]. In the recent years have the flat glass industry become more certain that $\mathrm{Na}_{2} \mathrm{SO}_{4}$ is the sulphur source and that Nickel originates from steel and reacts according to the chemical equilibria [24].

$$
\mathrm{NiFe}_{3}+\mathrm{Na}_{2} \mathrm{SO}_{4} \rightarrow \mathrm{Na}_{2} \mathrm{O}_{\text {glass }}+3 \mathrm{FeO}_{\text {glass }}+\mathrm{NiS}
$$

\section{Properties of nickel sulfide}

The most inclusions are less than $300 \mu \mathrm{m}$ in diameter $[50,51]$ since otherwise they would probably have been sinking faster than moving forward in the glass melt [51]. NiS, similar to other crystalline compounds, exists in different phases at different temperatures. The Ni-S phase diagram can be found in these references: [3034]. There are two phases of relevance that is frequently called $\alpha$ and $\beta$, the $\alpha$-phase is stable above $379^{\circ} \mathrm{C}$ while the $\beta$-phase is stable below $379^{\circ} \mathrm{C}$ [18]. The majority of the non-dissolved NiS inclusions [52] will most likely remain in the $\alpha$-phase upon rapid cooling. Other glass products that are annealed, most often, do not suffer from this as the NiS inclusions have in most cases sufficient time to transform into the $\beta$-phase. More importantly annealed glasses do not have significant central tensile stresses. In thermally strengthened glass, where the glass is rapidly cooled, the NiS inclusions are trapped in the high temperature $\alpha$-phase as a meta-stable condition. According to the thermodynamic rules the NiS inclusions will transform with time until the lower energy level is reached i.e. the $\beta$-phase. The phase transformation is a complex reaction and may involve several intermediate steps [35] but the speed is based on different sources of energy e.g. thermal energy or solar radiation. The phase transformation reactions are described more in detail in ref [53-56].The properties of a typical float glass (soda-lime silicate) and the different NiS phases are given in Table 1. As is given from Table 1, the NiS phases have higher thermal expansion coefficient so upon rapid cooling it contracts more than the glass leaving a small space between the inclusion and the glass. NiS occurs naturally in the form of the mineral Millerite which is the $\beta$-form of NiS $[32,57]$. The $\alpha$ and $\beta$ phase have different crystal structures, NiS- $\alpha$ has a distorted hexagonal close packed structure with the cations occupying the octahedral positions (NiAs crystal structure) [58] and the NiS- $\beta$ has a rhombohedral structure [59]. As a result of the phase transformation the NiS inclusions expands $2-4 \%$ which may theoretically cause local tensile stresses of up $615 \mathrm{MPa}$ due to hydrostatic pressure [35], however, it is more likely to be in the range of about 100 $\mathrm{MPa}[60]$. The theoretical expansion is about $4 \%[35,36]$ but experimentally have $2.2 \%[61]$ and $4.7 \%$ been shown [62]. More recently it has been showed that a volume expansion of more $2.5 \%$ is unlikely [63]. The tensile stresses are local and diminish only micrometers from the NiS inclusions but it can be sufficient tensile stresses to initially create micro cracks [64], see Figure 2. If this happens in the tensile zone of a thermally toughened glass can the residual tensile stresses make the micro cracks to propagate through large stress concentrations. Eventually will the cracks undermine the glass which causes total fracture into fragments according to the characteristic view of thermally strengthened glass. This may look like a "spontaneous" fracture. The location of the NiS inclusions is of course of importance and this was clear already from Ballantyne's pioneering study [28]. It shall though be noted that even though the NiS inclusion creates microcracks in the compressive zone and without propagating it will still be a weakening of the glass [65].

The first cases of spontaneous fracture due to NiS inclusions can be traced back to PPG Industries during the 1940s [29] but did not appear in the literature until

Table 1. Properties of float glass and the $\alpha$ as well as $\beta$ phase of NiS, values taken from ref [35].

\begin{tabular}{lccc}
\hline Properties & Float (soda-lime-silicate) & NiS $(\alpha)$ & NiS $(\beta)$ \\
\hline Elastic modulus & $70 \mathrm{GPa}$ & $80 \mathrm{GPa}$ & $70 \mathrm{GPa}$ \\
Poisson's ratio & 0.23 & 0.27 & 0.20 \\
Density & $2.51{\mathrm{~g} \cdot \mathrm{cm}^{-3}}^{-7}$ & $5.46 \mathrm{~g} \cdot \mathrm{cm}^{-3}$ & $5.25 \mathrm{~g} \cdot \mathrm{cm}^{-3}$ \\
Thermal expansion coefficient & $88 \times 10^{-7} \mathrm{~K}^{-1}$ & $163 \times 10^{-7} \mathrm{~K}^{-1}$ & $145 \times 10^{-7} \mathrm{~K}^{-1}$ \\
\hline
\end{tabular}


the 1960s [28]. Notable work has been performed on the understanding of NiS over the years [35, 36, 39, $42,43,46,56,66]$. The so called "butterly" (or double D) fracture has been suggested to be characteristic for NiS inclusion induced fracture, see Figure 3. However, the "butterfly" fracture is not believed to be a certain signature of spontaneous fracture as i) the glass needs to be intact to see it, ii) often mistaken for edge-fracture according to ref $[52,67]$.

Nickel sulphide is a chemical compound with different stoichiometric variations. A considerable amount of research has been focused on how the different properties of these variations behaves in thermally strengthened glass [39, 42, 49, 66, 68, 69]. The most common forms of $\mathrm{NiS}$ are $\mathrm{Ni}_{7} \mathrm{~S}_{6}, \mathrm{NiS}, \mathrm{NiS}_{1.03}, \mathrm{Ni}_{3} \mathrm{~S}_{2}$ and $\mathrm{Ni}_{3} \mathrm{~S}_{2}+\mathrm{Ni}$. In an electron microscope the $\mathrm{Ni}_{7} \mathrm{~S}_{6}, \mathrm{NiS}$, and $\mathrm{NiS}_{1.03}$ are most often (but not necessarily) gold-yellow and have an uneven surface, similar to a golf-ball, see Figure 2. These three forms are non-magnetic and may

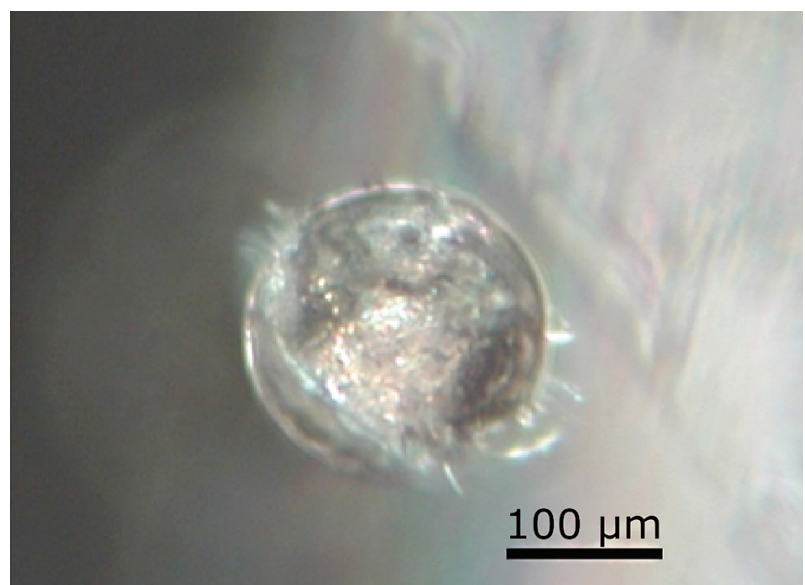

a) cause spontaneous fracture in thermally strengthened glass [42]. $\mathrm{Ni}_{7} \mathrm{~S}_{6}$ has another phase transformation temperature between the $\alpha$ and $\beta$ phase, $397^{\circ} \mathrm{C}$ [53]. It has also a much more rapid phase transformation and is therefore not considered a problem [70]. $\mathrm{Ni}_{3} \mathrm{~S}_{2}$ and $\mathrm{Ni}_{3} \mathrm{~S}_{2}+\mathrm{Ni}$ are greyish in the colour and have a relatively smooth surface in an electron microscope. These forms also have magnetic properties and have not been shown to cause spontaneous fracture in thermally strengthened glass [42]. In principally, according to ref. [70], is only $\mathrm{NiS}_{\mathrm{x}}$, where $\mathrm{x}$ is between 1 and 1.03 , a problem. The melting temperatures of $\mathrm{NiS}$ is $976^{\circ} \mathrm{C}, \mathrm{Ni}_{3} \mathrm{~S}_{2} 787^{\circ} \mathrm{C}$, $\mathrm{Ni}_{3} \mathrm{~S}_{4} 995^{\circ} \mathrm{C}$ and $\mathrm{NiS}_{2} 1022^{\circ} \mathrm{C}$ [70]. Impurities in the $\mathrm{NiS}$ inclusions changes the properties of the inclusions and impurities such as $\mathrm{Fe}$ and $\mathrm{Cu}$ are common while most other metals are oxidized and dissolved in the glass melt [56]. Fe-impurities in the order of about $1 \%$ in the $\mathrm{NiS}$ inclusions involves a slower phase transformation between the $\alpha$ and the $\beta$ phase. In practice the NiS

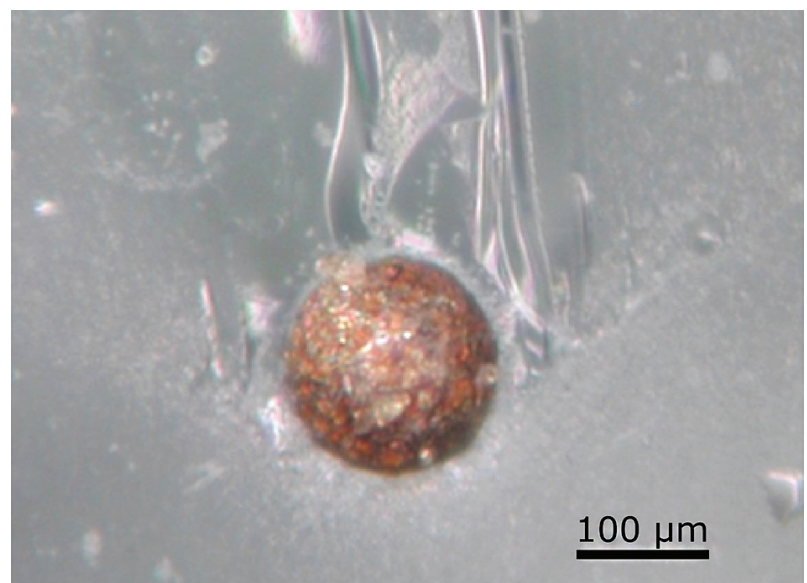

b)

Figure 2. Micro cracks around a NiS inclusion in glass (a) and NiS inclusion on fracture surface of glass that was a case of spontaneous fracture (b); reproduced with permission from J. Barry, originally published in ref [64].

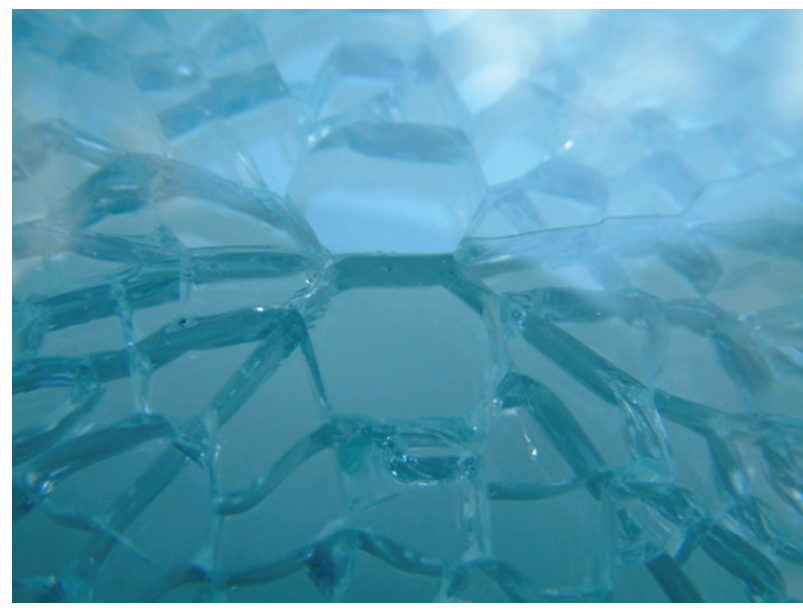

a)

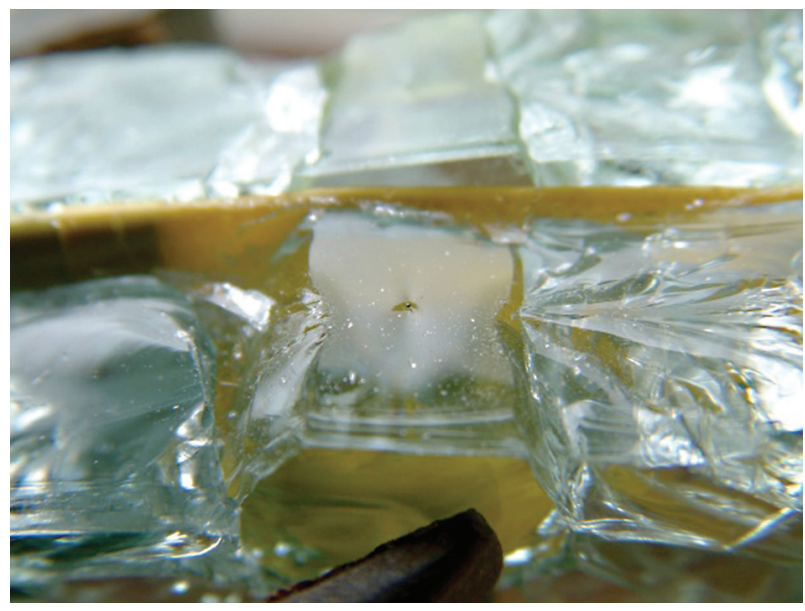

b)

Figure 3. "Butterfly" fracture with NiS inclusion in the middle (a) and NiS inclusion in a fractured glass (b); photos provided by J. Colvin.

Ceramics - Silikáty 61 (3) 188-201 (2017) 
inclusions are always containing some iron impurity $\mathrm{Ni}\left(\mathrm{Fe}_{\mathrm{z}}\right) \mathrm{S}_{\mathrm{x}}$, the contents vary between $50.1-52.7$ at. \% $\mathrm{S}$ and $0.11-1.62$ at. $\% \mathrm{Fe}$ [55].

The NiS phase transformation studies have in the more recent years become more frequent, as has better equipment. Previously has Differential Scanning Calorimetry (DSC) been frequently used in the studies $[39,43,53,54,70,71]$ but one of the studies suggests that the phase transformation transforms via a martensitic mechanism i.e. the change of the crystallographic structure depends on displacement mechanisms [62]. This contradicts the DSC studies that generally show that the $\alpha \rightarrow \beta$ transformation give an exothermic DSC graph while the opposite transformation give an endothermic DSC graph. The transformation has also been shown to become slower for overstoichiometric phases and with iron impurities i.e. the DSC studies suggest that the transformation depend on diffusion mechanisms [70]. More can be read about phase transformation theory in ref [72]. Due to the contradiction has a more accurate study been performed in the temperature range $200-300^{\circ} \mathrm{C}$ $[55,56]$. Different characteristic surface structures for the $\alpha \rightarrow \beta$ phase transformation have been identified i) globular morphology, ii) lamellar morphology, iii) precipitation of $\mathrm{Ni}_{3} \mathrm{~S}_{4}$, iv) rough lamellar morphology, v) lamellar morphology without precipitation of $\mathrm{Ni}_{3} \mathrm{~S}_{4}$ and vi) block morphology [56]. The different morphologies are steps to a better understanding of the phase transformation at different temperatures with the purpose to use the information to improve and optimize the HST method [73]. It shall though be noted that the kinetics of the phase transformation is further complicated by the fact that the inclusions are in practice composed by several different stoichiometric $\mathrm{Ni}_{\mathrm{x}} \mathrm{S}_{\mathrm{y}}$ variations $[74,75]$.

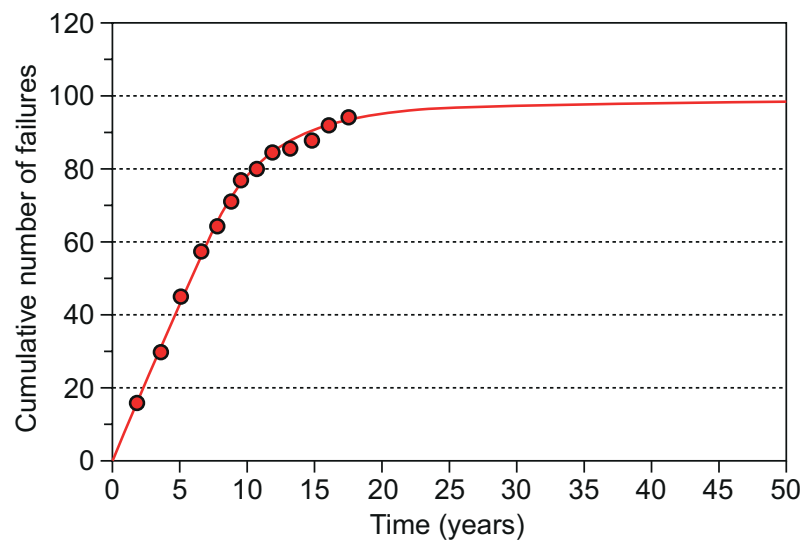

Figure 4. Cumulative number of failures caused by NiS inclusions over time. The model (line) is based on a Weibulldistribution while the dots are actual data from a real building. Figure is taken from ref [67] (Creative Commons Attribution Share-Alike 3.0) but it is based upon data from ref [29, 30], permission from L. Jacob has been granted.
Spontaneous fracture - frequency and time aspects

Thermally strengthened glass with NiS inclusions may fracture after a few days, months, years and decades, the latter is though seldom. The most spontaneous fractures occur within 2 to 7 years from when it was strengthened and thereafter linearly decays proportional to the logarithm of time $[29,30,60]$, see Figure 4 . Bowler-Reed claims that no spontaneous fracture have occurred beyond 30 years of time [52]. A reason for the delay in time is the space between the NiS inclusion and the glass as result of the differences in thermal expansion coefficient, cf. Table 1. The space gives the NiS inclusion some time volume and time to expand before it starts to hydrostatically press the glass. The time to failure depend on several different factors e.g. purity of the NiS inclusion, location of the inclusion, strengthening level, size of inclusions and its bubble where the inclusion can be found as well as environmental factors such as temperature, wind load, size of the glass sheet and how the glass is mounted [18, 30, 70].

As a rough estimate, spontaneous fracture due to NiS inclusions occurs at a frequency of 1 out of 500 glass sheets of average size [76]. That is probably the frequency easiest to grasp [67] even though assumptions have to be made e.g. 1 out of $500 \mathrm{~m}^{2}$ of $4 \mathrm{~mm}$ glass sheets. The amount of NiS inclusions ultimately depends on the glass manufacturers' quality assessment in order to minimize the amount of $\mathrm{Ni}$ in the glass. As all float glass manufacturers use $\mathrm{Na}_{2} \mathrm{SO}_{4}$ as fining agent, the sulfur cannot be minimized. There are no guidelines in the European standard for thermally strengthened glass in buildings (EN 12150) how to minimize inclusions of NiS. Generally, in order to minimize the number of NiS inclusions the glass manufacturers' must have an accurate control of the raw materials, regular maintenance of tank furnaces and practice clean habits for the production and the handling of raw materials. In order to minimize "spontaneous" breakage it is also important to practice clean habits in the annealing lehr, tempering furnace and careful handling during transport and mounting of the thermally strengthened glass. There is also the possibility to use heat-soak test (HST) the strengthened glass but HST-tested glasses may spontaneously fracture, but the risk is minimal [60]. NSG Pilkington [41] have made significant quality assessment in order to minimize the amount of NiS inclusions in the glass e.g. regularly controlling the raw materials by letting them pass through a magnetic separation technique that removes all magnetic compounds that then can be analyzed chemically. Similar scanning should be possible to perform just before putting in the raw materials in the tank furnace. Improved optical quality systems in the float lines may as well sort glasses with defects [77], even larger NiS inclusions $(>100 \mu \mathrm{m})$. Smaller NiS inclusions are though still too small $(<100 \mu \mathrm{m})$ to be detected and since these cannot be detected no glass manufacturer can guarantee the glass to be completely 
free of NiS inclusions [41]. As of today, with the continuous improvement of the quality systems of float glass manufacturers the issue with NiS inclusions' is rare [56], however, it can in some batches get an unusually significant impact because of a significant amount of impurities in a raw material batch that have slipped through the tank furnace. Reeves [78] has reviewed the development on the perspectives of spontaneous fracture in glass throughout the history and what mitigating measures previously has been done.

The central tension is a necessity for fully thermally strengthened glass to be classified as safety glass but also a necessity for NiS inclusions to cause real spontaneous fracture. Heat strengthened glass is less prone to spontaneously fracture but it can of course still happen $[41,52]$, there have been numerous examples over the years [30]. Brungs and Sugeng [44] suggests that heat strengthened glass is developed as a mitigation measure to reduce the amount of $\mathrm{NiS}$ inclusions but also persist that heat strengthened glass can spontaneously fracture but only if the NiS inclusions have a diameter of more than $0.5 \mathrm{~mm}$. That size of NiS is very rare but more importantly is it incorrect [50], NiS inclusions in size of $<100 \mu \mathrm{m}$ may cause heat-strengthened to spontaneously fracture. There have been studies focusing on the critical size of NiS inclusions that can cause spontaneous fracture, in the first attempt, the results were unreasonable [36]. In Swain's pioneering study [35], fracture mechanics was used to calculate a minimum size of $50 \mu \mathrm{m}$ and this has more recently been confirmed by Gelder [51]. The inclusions have therefore been categorized in two different classes, critical NiS inclusions $(>50 \mu \mathrm{m})$ and sub-critical inclusions $(<50 \mu \mathrm{m})$. Sub-critical inclusions may still cause spontaneous fracture if the glass is subjected to additional tensile stress such as thermal shock or bending. External loads, e.g. bending, affects the stress profile during loading i.e. the parabolic stress

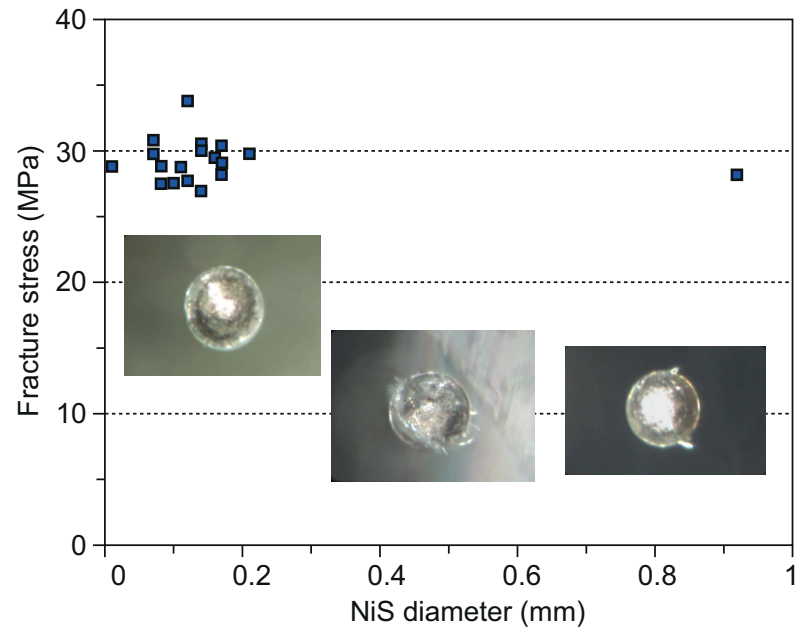

Figure 5. Background graph: fracture stress as calculated from Equation 1 using the fracture mirror data provided by Jacob in ref [18] using a $\mathrm{KM}$ value of $2 \mathrm{MPa} \cdot \mathrm{m}^{1 / 2}$. The inset photos were kindly provided by J. Barry. profile is changed. At large deformations (more than $75 \%$ of the thickness of the glass) is the bending-load changed from giving pure bending profile to be of membrane stress profile type [67]. This can significantly affect the risk of spontaneous fracture [18]. Based upon the theoretical relation on the diameter of the NiS inclusions and the tensile stress increase it is enough with only 1.4 $\mathrm{MPa}$ to cause spontaneous fracture. It corresponds to an inclusions of a bit less than $50 \mu \mathrm{m}$ if the inclusion is located in the central tension zone with approximately $100 \mathrm{MPa}$ of surface compressive stress [51]. The $1.4 \mathrm{MPa}$ tensile stress increase corresponds to an increase of the tension level by $2.8 \%$. Glass in general is very sensitive to tensile stresses e.g. from bending or thermal shock. Thermal shock may give tensile loads up to several tenths of $\mathrm{MPa}$ [79]. In normal cases thermal strengthened glass has no problems whatsoever to withstand such loads (unless seriously scratched). Based upon spontaneously fractured glass in HST and from buildings, a distribution of the different sizes of the NiS inclusions are given in ref [70]. The average value is about $217 \mu \mathrm{m}$ in diameter where the range is between 50 to $650 \mu \mathrm{m}$. The locations of the NiS inclusions are also given in ref [70] and all are located in the central tension zone.

Jacob [18] has studied the fracture mirrors of spontaneously fractured glasses and suggested that there is a mathematical relation between the fracture stress and the fracture mirror. The fracture mirror is a term within fractography and is something that arise as the crack propagates, it is generally a measure of the crack velocity [80]. However, Jacob [18] used $K_{I C}$ the critical stress intensity factor instead of $K_{M}$ which is the crack intensity factor at mirror formation. It should be used in describing the relation between the fracture stress and the mirror radius [81]. $K_{M}$ is also called the mirror constant and sometimes denoted $A_{M}[23,82,83]$. The fracture mechanics description of the relation of the fracture stress and the mirror radius should therefore be as described in Equation 1 [83] where $\sigma_{f}$ is the fracture stress, $\mathrm{C}_{\mathrm{M}}$ is the mirror radius and $\mathrm{K}_{\mathrm{M}}$ is in the range of 1.9 to $2.1 \mathrm{MPa} \cdot \mathrm{m}^{1 / 2}$ [23]. From Figure 5 it is clear that the fracture stress is independent from the NiS diameter i.e. the size of the NiS inclusion give a lower or higher stress upon spontaneous fracture which suggests that microcracks around the inclusions are the major stress concentrators and origins of fracture.

$$
\sigma_{f}=\frac{K_{M}}{\sqrt{C_{M}}}
$$

The frequency of NiS inclusions has been a subject of many studies. As previously mentioned, Napier and Blakely [76] reports that there are $1 \mathrm{NiS}$ inclusion per 500 glass sheets of normal size. Barry [66] gives an estimate of about $0.8 \%$ of the fractured glass panels suffer from spontaneous fracture. Jacob [29] specifies $1.73 \% \mathrm{NiS}$ inclusions based upon data from buildings with strengthened glass sheets, $306 \mathrm{NiS}$ inclusions out 
of 17760 glass panels in 12 years of time. Then there are specified values that are less easy to grasp except for perhaps glass manufacturers given in weight. Barry and Ford [42] specify a value of $5 \mu \mathrm{g}$ NiS per 1.1 tons of glass. Jacob [29] specifies a value of $1 \mathrm{NiS}$ inclusion per 880 tons of glass, even though that the study is based upon a data from a company that strengthen glass and that over five years had $1 \mathrm{NiS}$ of 450 tons of glass. Gelderie and Kasper [24] state a frequency of $1 \mathrm{NiS}$ inclusion in 6 to 12 tons of float glass and $1 \mathrm{NiS}$ inclusion in 1.38 tons of alkaline earth silicate glass (fire protection glass). Brungs and Sugeng [44] give a frequency of $1 \mathrm{NiS}$ in 8 tons of glass but if there are contaminations there can be up to $13 \mathrm{NiS}$ inclusions per ton of glass. The frequency values that are reported in the literature do not all correspond to each other. This may depend on varieties in the quality assessment of glass manufacturers and a contaminated glass batch can probably give a high impact in the statistics [29]. Furthermore, as the glasses may suffer from delayed spontaneous fracture it is quite difficult to investigate and would naturally come with rather large error bars. Laminated glass is easier to investigate as the fractured glass is still intact in its location but nonlaminated glass is difficult to investigate. In general are NiS inclusions rather rare but if we consider that there are $1 \mathrm{NiS}$ inclusion per $500 \mathrm{~m}^{2}$ glass sheets of $4 \mathrm{~mm}$ thickness, there should be numerous spontaneous fractures every year. The probability is higher that it occurs in a building that uses higher amount of strengthened glass and modern architecture often involves much glass.

\section{DISCUSSION}

The glass industries have over the years been trying to prevent spontaneous fracture with the main purpose to reduce risks but also costs. There are three general criteria that makes a preventive method useful and efficient; i) cost effective, ii) eliminate costs for replacement of strengthened glass after spontaneous fracture (often the most costly) and iii) prevent personal injuries of people that happens to be immediately nearby when the glass spontaneously fractures [67]. So far has none of the suggested methods satisfied the industry with all three criteria, therefore is the industry still interested in alternative methods. An option is of course to reduce the amount of thermally strengthened glass that is used and reasonably the less strengthened glass, the less amount of spontaneous fracture. This is something that "Building Envelope Design Guide" [84] have taken a mental note of, thermally strengthened glass shall only be used when it is a demand on the strength and it is recommended to use laminated glass where it is probable and appropriate. Lamination supports the glass to be intact in its location and eliminates the risk of personal injuries. However, there are drawbacks; it increases the weight and the cost, besides it does not replace the cost of exchanging a spontaneously broken glass. Though in most cases, as have been referred to before, glass sheets fracture because of other reasons than inclusions and as a matter of fact many glass fractures can be avoided by proper design, manufacturing and installation [27].

As has been described previously in the paper, it is very difficult to control and eliminate $\mathrm{Ni}$ in the glass melt; the sulfur is even more difficult. The reason to why it is difficult is the simple reason that it is almost infinite amounts of Ni that is required to create critical inclusions. $\mathrm{NiS}$ is difficult to dissolve in the glass melt but it is not insoluble, it just requires more time in ordinary soda lime silicate glass $[44,56]$. Different glass compositions have different properties, Brungs and Sugeng suggest to adjust the glass composition (add an oxidation agent) so that the dissolution rate is increased [44]. The glass composition could be standardized for thermally strengthened but so far has the cost been considered to be too high. Recently has a study been published where NiS inclusions have experimentally been simulated through additions but also additions of $\mathrm{ZnSO}_{4}$ as oxidation agent which increased the dissolution rate [40]. NiS inclusions have also been studied in borosilicate and aluminasilicate glass, the study showed that there is no risk for spontaneous fractures [68]. Alkaline earth silicate glass (fire protection glass) considerably increased the risk for spontaneous fracture [24].

\section{Heat Soak Test (HST)}

There is a standardized post-strengthening heat treatment method, a so-called Heat Soak Test (HST), that can be used for separating glass sheets with NiS inclusions [30]. HST was first regulated in the German standard DIN 18516 but has in later years been replaced by EN 14179 [85], that has by now already been published in a couple of versions 2005 and last 2016. The EN 14179:2005 version involves a heat treatment of 2 hours at $290 \pm 10^{\circ} \mathrm{C}$, where the phase transformation of $\alpha$ to $\beta$ NiS inclusions are strongly accelerated [86]. It was based on research [70] that claim less than 1 out of 10000 spontaneous fracture were likely to occur after two hours of HST [87]. It is a reduced heat treatment duration compared to DIN 18516 which involved a heat treatment of 8 hours but it also took especially care that there are glass sheets with coatings (e.g. low-emission coatings [88]) [51]. HST with coated glass also involves another issue, that the coatings are degraded because of the heat treatment [44]. HST is a destructive method that according to statistics remove more than $98.5 \%$ with $95 \%$ confidence of the dangerous NiS inclusions [60, 70]. The method implies an additional cost of thermally strengthened glass [29], not only because of the heat treatment but also since it is a destructive method. It may occur that as glass sheets spontaneously fracture in HST furnace also other nearby standing glasses are damaged or even fractured [64]. Another disadvantage 
of the HST is that it reduces the strengthening level due to stress relaxation $[89,90]$, it affects the strength of the glass but also the fracture pattern. In the EN 14179 standard the HST furnace is required to be calibrated, however, the quality of the calibration method has not been proved. The draft version of EN 14179 did not give any heat nor cooling rate [30] and that has been proven to be important as about $80 \%$ of the glasses already fractures during the heating phase of the HST, the rest fractures at $290 \pm 10^{\circ} \mathrm{C}$ [70]. Refs [70, 91] are the basis of the EN 14179 standard, a study where 224 glass sheets were spontaneously fractured in HST or in buildings where 212 glass fractures were caused by $\mathrm{NiS}$ inclusions. It was confirmed by crystallographic analysis that all of the NiS inclusions were $\beta$-NiS, which indicates that the phase transformation has taken place. In the remaining spontaneous fractures it involved salt bubbles ( 2 glass sheets), inclusions of refractories (3 glass sheets) and 7 glass sheets spontaneously fractured without a known reason other than possibly thermal shock or damages from nearby standing spontaneously fractured glass sheets [70]. Kinetic phase transformation data is presented in [70] and based upon the data could a theoretical NiS phase transformation model be calculated according to Kissinger's method [92]. However, the theory and practical industrial test were not matching, a reason for that was the uneven heating of the glass as the temperature is measured in the air. A lot of detailed information has now been updated to the new standard EN 14179:2016 which were induced by different proposals to enhance the HST method [30, 51, 93-96]. Gelder [51] has already prior to the 2005 version suggested to perform an extra thermal shock test in order to separate further glass sheets, in particularly those with sub-critical NiS inclusions. The other proposals involved reduced heating rate (rejected by other researchers [62]) and also reduce the holding temperature of the HST. The lower holding temperature $\left(240 \pm 20^{\circ} \mathrm{C}\right)$ is based upon that there is risk that higher temperatures may involve a re-transformation of $\mathrm{Ni}_{1-\mathrm{x}} \mathrm{S}$ stabile $\beta$-phase since that particularly stoichiometric form has a low phase transformation temperature $\left(282^{\circ} \mathrm{C}\right)[32,94]$. Jacob and others $[30,96]$ discussed the HST methods both advantages and disadvantages, they suggest a two-step method where first a treatment at $240 \pm 20^{\circ} \mathrm{C}$ is performed (similar to [94]) followed by a treatment at $290{ }^{\circ} \mathrm{C}$ (in accordance with [70]). A lower holding temperature has been confirmed to improve the HST method [95] and has been adopted in EN 14179:2016. A two-step heating method in order to reduce the stress relaxation that is induced by the HST was also proposed [95]. It involves a heating treatment up to $180-200^{\circ} \mathrm{C}$ and holding for $30-60 \mathrm{~min}$ in order to increase the nucleation rate followed by a heating up to $260^{\circ} \pm 10^{\circ} \mathrm{C}$ in $1 \mathrm{~h}$. As it is rather complex with a two-step method an alternative approach is also suggested [95], a slower heating $\left(1^{\circ} \mathrm{C} \cdot \mathrm{min}^{-1}\right)$ from $170^{\circ} \mathrm{C}$ to $260 \pm 10^{\circ} \mathrm{C}$ and a shorter holding duration $(1.5 \mathrm{~h})$.

The HST method is the only method that is standardized to cope with the spontaneous fracture issue and the industry at least partly uses it. The method is capable to handle large scale production. The efficiency is hard to define and prove because of the problems to gather accurate data but most manufacturers' can give a certificate of $95 \%$ reliability. Some may also give a certificate of $98.5 \%$ reliability [70] but a $100 \%$ guarantee cannot be given. In practical sense, the $98.5 \%$ means that there is a $1 \%$ risk of one spontaneous fracture on a building with $10000 \mathrm{~m}^{2}$ flat glass with an average thickness of $8 \mathrm{~mm}$ per year [87]. HST has in general been used more frequently in Europe than in the US. In the US has either the HST not been used at all or it has been used at a lower temperature and shorter holding duration which may have caused poorer results, this may have increased the criticism of the HST [26]. Perhaps with the recent EN 147179:2016 standard, where more effort has been put on details, a better outcome will be given. However, so far there are no demands in the EN 12150 standard that thermally strengthened glasses shall go through HST; therefore the HST is also less frequently used.

\section{Alternative preventive methods}

Over the years there have been several alternative methods suggested instead of the HST method [67, 89, 97] e.g. laser imaging, ultrasonic or controlled mechanical loading. Another problem where a solution is needed is controlling glasses already mounted in e.g. buildings. When a glass spontaneously fracture occur in a building or e.g. shower door the glass is normally replaced but a proactive interested partner may also wish to prevent it from happening in the future [98]. An expensive option is to remove all the glasses and perform the HST unless it has already been done. Other methods are also costly because of expensive equipment and the time effort of qualified staff. A survey of the alternative methods, for production and for mounted glasses, is given below followed by a discussion.

Ultrasonic [67], linear or non-linear [99], is a method that is based on sound waves and corresponding echoes to get information of the material. The results should be analyzed by qualified staff and the results are often difficult to interpret. Perhaps with more research effort algorithms can be employed, especially if put into the production line. For scanning glass sheets that have been put into buildings it is time consuming and is so far not confident enough as the NiS inclusions are very small, every inclusion has to be judged if it is critical motivating replacement or not [67]. Ultrasonic has more potential to be used in production than on buildings and it is also a method that perhaps can integrate the monitoring of the strengthening level as well [100-102].

Laser imaging [67] uses the light scattering pheno- 
menon that is created as light interacts with particles or inclusions. The method involves sending laser through the glass and detection of the scattering on the other side. Laser is employed because it is concentrated monochromatic light which makes it easier to detect the light scattering. The ability to model the light scattering effect of different particles size is crucial for the possibility to interpret the result. If employed on glass sheets in a building it is similar to ultrasonic, time consuming and qualified staff is required. The method is slightly better than ultrasonic because it is possible to make a better estimation of the size of the inclusion. Laser imaging is similar to the scattered light method that is employed to analyze stresses in strengthened glass $[103,104]$. Scattered light method has also been tested for identifying NiS inclusions in glass [105], out of 1135 tested glass sheets could 17 defects larger than $60 \mu \mathrm{m}$ be found. However, for determining if it is NiS inclusions another method has to be employed. Through Energy Dispersive Spectroscopy (EDS) could it be determined that only 1 of these 17 defects was NiS, most others were bubbles. Without determining the defects it would though be possible to sort out these as low-strength glasses and use them in places where neither spontaneous fracture nor the lower strength is an issue, similar to the study of Molnar and Bojtár [25]. The method is most suited to be used in production facilities where strengthening level and defects can be determined with the same equipment. Photo method is a result of collaboration between University of Queensland and the company Resolve Engineering $\mathrm{P} / \mathrm{L}$. The method is described more in detail in refs $[64,97]$. The method is divided into three steps where the first step is to photograph the glass in a certain angle (high resolution photo). As a result of inclusions a characteristic pair of dots can be seen. In the second step the photo is scanned with use of microfiche, a type of microfilm. The dot pairs must be identified and the distance between the dots can be used to determine the location of the inclusions. The identified inclusions that are located in the central tension zone are investigated by a third step with magnifying glass or a light microscope. The NiS inclusions can be sorted by the characteristic color and the surface structure, however not necessarily [47]. The method is time consuming and dependent on qualified staff that photograph and examine the photos. Specialized equipment also makes it relatively expensive. In total were 4194 glasses tested in a building and 53594 inclusions were identified where of 291 were NiS inclusions in the central tension zone. Those tests were performed in 1995 and with todays modernized digital camera system it most certainly could be more efficient. It shall though be noted that a $35 \mu \mathrm{m}$ pixel size is required to determine an inclusion of $70 \mu \mathrm{m}$ size. To investigate $3 \mathrm{~m}^{2}$ with that kind of resolution would require $3 \mathrm{~GB}$ with data [64]. The test that were done in 1995 would have required 5 TB of data to be collected, stored and processed, it is a considerable amount of data but not today for those working with computer aided engineering (CAE). Image analysis is a powerful tool that in the recent years have become a comprehensive research topic and can be used for a wide range of applications on glass e.g. homogeneity [106], wearing [107] and forming [108]. The demand for image analysis is of course to have a sufficient resolution for the defect to be identified and a suitable algorithm.

Another method combines the photo method with the laser imaging method, it is described in detailed in ref [98]. In contrast to the laser imaging method, which is based on transmission, the combined method is based upon reflection. When light is transported into a glass it is refracted due to the different refractive index compared to air. At a certain angle the light can be introduced into the glass so that it is totally internally reflected inside the glass, however, light is absorbed in the glass and will eventually be too weak to be detected. Ref [98] describes the equipment that is mounted to the glass with vacuum and that light is totally internally reflected in the glass. The inclusions are then scattering the light so that they are easily detected. It is though not possible to determine if the inclusions are critical NiS inclusions but by using an angled camera it would be possible to determine the depth of the inclusions.

The alternative methods are summarized in Table 2, comparing advantages and disadvantages. Non-destructive methods (e.g. laser and ultrasonic) have been more frequently suggested but often is the equipment relatively expensive. Even if these can be automatically processed in the production each individual glass sheet has to be tested, it would significantly reduce the production rate unless there are new innovations. Also unless more effort is devoted to the research there is no guarantee that it fully separates the glass sheets with NiS inclusions. The results from the ultrasonic and laser methods must be interpreted by qualified staff unless an algorithm is developed for the purpose and it remains to be demonstrated if it is possible. The error might still be significant since the NiS inclusions are very small. Controlled mechanical loading also has its drawbacks, the calibration quality is of outmost importance otherwise can the mechanical load give rise to a considerable amount of fractured glass than is necessary. Fluorescence of NiS particles in glass has previously not been studied and could be an alternative to be demonstrated. Nanoparticles of NiS have been shown to emit light at $550 \mathrm{~nm}$ when excited at 350 and $400 \mathrm{~nm}$ [109]. Excitation at $400 \mathrm{~nm}$ inside glass could be possible while at $350 \mathrm{~nm}$ the absorption in the glass is probably too high. Raman spectroscopy has been suggested by Bishop et al [110] but it is perhaps difficult to apply on a larger scale. Similar to CT scan, that has limitations of the size of the area to be investigated as well as resolution, most industrial CT scan instruments are in the range of $100 \mu \mathrm{m}$ in resolution but there are instruments with resolutions of $10 \mu \mathrm{m}$ available. As it is today, none of the alternative methods are suitable for large scale 
production but there are those which have significant advantages compared to disadvantages. Non-destructive methods that are also able to classify other defects that significantly lower the strength of the glass [25] and at the same time separate glasses with $\mathrm{NiS}$ inclusions are alternatives that are worth investigating, it both has an academic and industrial interest. The other alternative, measuring the stress profile and the strengthening level, that some of the alternative methods give, is not as appealing as strength classification. The possibility that silicon particles also give spontaneous fractures [37] could be solved with strength separation methods as well, however, more research that demonstrates this fact is required. The option raised by Brungs and Sugeng [44] and continued by Wasylak et al [40] altering the glass composition in order to dissolve NiS faster in the glass melt is interesting. By altering the glass composition it is tentatively possible to simultaneously increase the damage resistance [111-113] which ultimately leads to a stronger float glass $[114,115]$ which can lead to thinner

Table 1. Comparison of different alternative method to detect and separate NiS inclusions in thermally strengthened glass. The methods are described in chapter 6 and 7.

\begin{tabular}{lll}
\hline Alternative method & Advantages & Disadvantages \\
\hline $\begin{array}{l}\text { Reducing the amount of } \\
\text { thermally strengthened glass }\end{array}$ & $\begin{array}{l}\text { Reduces the possibility for spontaneous } \\
\text { fractures. }\end{array}$ & $\begin{array}{l}\text { Less aesthetical option and reduces the safety } \\
\text { opportunity with glass. }\end{array}$ \\
\hline
\end{tabular}

Laminated glass as safety Strongly reduces the possibilities for personal glass [44] injuries.
More expensive option and does not replace the cost if spontaneous fracture occurs. Increases the weight of the glass products.

In principal impossible but can be minimized through minimizing the amount of $\mathrm{Ni}$ in the glass melt, most likely varies between glass manufacturers.

$\mathrm{NiS}$ in the glass melt [47]. $\quad$ satisfying results.

Other glass compositions $[44,47]$

Renders satisfying results and the glass composition can be optimized for increased scratch resistance and crack resistance [112].

Demands research and development in order to be introduced into flat glass production.

Removes $>98.5 \%$ (with a $95 \%$ confidence) of the glasses with NiS inclusions if performed

Heat Soak test (HST) [70] $\begin{aligned} & \text { of the glasses with NiS inclusions if perform } \\ & \text { properly and is today the only standardized }\end{aligned}$ method.

Destructive method that is relatively expensive. Despite being a European standard it has failed to reach wide usage.

Combination of HST and Removes glasses that have microdefects and Thermal shock [51] could be integrated with the HST.

Destructive method that is relatively expensive, effectiveness remains to be demonstrated.

A method that potentially can detect more than just NiS inclusions and with the possibility to automatization. Similar to the light scattering method that also measure the stress profile in glass [103, 104].

Laser imaging or light scattering method [105]

A method that potentially can detect more than just NiS inclusions [100, 102].

Photo method and/or image A method that potentially can separate low analysis.

strength glasses as well. Can be automated with image analysis.

A method that potentially can separate low strength glasses as well.

CT Scan [25]

Raman spectroscopy $[110$ 119]

Sensitive to both larger and small particles with the possibility to be automatized.

Potentially sensitive to both larger and small particles with the possibility to be automatized.

Flourescence Excitation can be made performed at $400 \mathrm{~nm}$ [109].
Further research and development is required to validate the method.

Further research and development is required to validate the method.

Limited by the resolution of the images and the amount of data that needs to be processed.

Expensive equipment needed, resolution depends on the type of equipment. Limited by the amount of data that needs to be processed and resolution. Research and development is needed so that the method is possible to use in larger scale.

Expensive equipment needed and equipment that needs development so that the method is possible to use in larger scale.

Method has not yet been demonstrated for this purpose. Expensive equipment needed and equipment that needs development so that the method is possible to use in larger scale. 
glasses. For example has not NiS inclusions been found to cause spontaneous fracture in alumina silicate glass which recently is used much more frequently because of its benefits for chemically strengthened glass [2, 3, 116-118]. Additionally, optimizing the glass composition properties for thermal strengthening can pave the way for a standard glass composition for thermally strengthened "safety" glass in the future.

\section{CONCLUSION}

Nickel sulphide inclusions are still a continuous problem for the glass industry, mainly flat glass industry. The amount of NiS inclusions has though been minimized by minimizing the amount of $\mathrm{Ni}$ in the glass melt. As thermally strengthened glass is fractured it gives small blunt glass fragments that in unfortunate situations may give minor cut injuries to humans or animals. Increased surface compressive stresses of the glass increases the strength but also the central tension that gives the frangibility characteristics and may be observed as explosive as the glass fractures. Despite many years of research devoted to NiS inclusions and spontaneous fracture has not a unified and generally accepted method been reached. The heat soak (HST) method has received the most impact and has become a standard but there are significant drawbacks with the method. The three major drawbacks are i) it is relatively expensive, ii) it reduces the strengthening level and iii) it is destructive. The alternative methods require development before they can be proved to replace the HST method. Spontaneous fracture is rare and the flat glass industry will perhaps only justify investing in the problem if it comes with other advantages such as strength classification, measurement of strengthening level or standardized glass composition for thermally strengthened glass. An optimized glass composition that eliminates dangerous NiS inclusions and that can give stronger and thinner thermally strengthened glass by increased damage resistance and a composition optimized for thermal strengthening can be a route forward.

\section{Acknowledgement}

Funding provided through the initiative Smart Housing Smailand, with funding from the region's public and private sectors and from Vinnova program VINNVÄXT (2013-02312), is greatly acknowledged. J. Colvin at John Colvin Glass Consultant J. Barry at Queensland University of Technology are greatly acknowledged for providing photos.

\section{REFERENCES}

1. Gardon R., (1980). Thermal Tempering of Glass, in: Uhlmann D.R., Kreidl N.J.(eds.): Glass Science and Tech- nology vol 5 Elasticity and Strength in Glasses, Academic Press, New York. p. 145-216.

2. Karlsson S., Jonson B., Stålhandske C. (2010): The Technology of Chemical Glass Strengthening - a Review. Glass Technology - European Journal of Glass Science and Technology Part A, 51(2), 41-54.

3. Karlsson S., Wondraczek L., (Accepted, In Press). Strengthening of Oxide Glasses, in: Richet P., (ed.): Encyclopedia for Glass Science, Technology, History and Culture, John Wiley \& Sons Inc.

4. Tang Z., Abrams M.B., Mauro J.C., Venkataraman N., Meyer T.E., Jacobs J.M., Wu X., Ellison A.J. (2014): Automated Apparatus for Measuring the Frangibility and Fragmentation of Strengthened Glass. Experimental Mechanics, 54(5), 903-912. doi:10.1007/s11340-014-9855-5

5. Gulati S.T. (1997). Frangibility of Tempered Soda-lime Glass Sheet. In: Glass Processing Days. Tampere, Finland.

6. Tang Z., Mauro Y.Z., Gee C., Duffy D.L.J., Meyer T.E., Abrams M.B., Walker K.A., Mauro J.C. (2015): Methods for Measurement and Statistical Analysis of the Frangibility of Strengthened Glass. Frontiers in Materials, 2, 1-8. doi:10.3389/fmats.2015.00050

7. Guillemet C. (1990): Annealing and tempering of glass. Journal of Non-Crystalline Solids, 123(1-3), 415-426. doi:10.1016/0022-3093(90)90813-2

8. Schaeffer H.A. (1983). Thermal and Chemical Strengthening of Glass-Review and Outlook, in: NATO advanced research workshop entitled strength of glass; Strength of Inorganic Glasses. Algarve, Portugal.

9. Donald I.W. (1989): Review: Methods for Improving the Mechanical Properties of Oxide Glasses. Journal of Materials Science, 24(12), 4177-4280. doi:10.1007/ BF00544488

10. Brodsley L., Frank C., Steeds J.W. (1986). Prince Rupert's Drops. Notes and Records of the Royal Society of London, 41(1), 1-26. doi:10.1098/rsnr.1986.0001

11. Hooke R. (1665). Observation vii. of some phaenomena of glass drops. In: Micrographia or Some Physiologial Descriptions of Minute Bodies made by Magnifying Glasses with Observation and Inquiries thereupon. London, pp. 33-44.

12. Chaudhri M.M. (2006): Explosive disintegration of thermally toughened soda-lime glass and Prince Rupert's drops. Physics and Chemistry of Glasses - European Journal of Glass Science and Technology Part B, 47(2), 136-141.

13. Bochkov M., Gusenkova D., Glushkov E., Zotova J., Zhabin S.N. (2016): Resistive method for measuring the disintegration speed of Prince Rupert's drops. European Journal of Physics, 37(5), 055707. doi:10.1088/01430807/37/5/055707.

14. Chaudhri M.M. (2009): The role of residual stress in a Prince Rupert's drop of soda-lime glass undergoing a selfsustained and stable destruction/fracture wave. Physica Status Solidi (a), 206(7), 1410-1413. doi:10.1002/pssa. 200925006.

15. Nielsen J.H., Olesen J.F., Stang H. (2009): The Fracture Process of Tempered Soda-Lime-Silica Glass. Experimental Mechanics, 49(6), 855-870. doi:10.1007/s11340008-9200-y

16. Mognato E., Barbieri A., Schiavonato M., Pace M. (2011): Thermally Toughened Safety Glass: Correlation between Flexural Strength, Fragmentation and Surface 
Compressive Stress, in: Glass Performance Days, pp. 115118 .

17. Lee H., Cho S., Yoon K., Lee J. (2012): Glass Thickness and Fragmentation Behavior in Stressed Glasses. New Journal of Glass and Ceramics, 2(4), 116-121. doi:10.4236/njgc.2012.24020

18. Jacob L. (1997). Factors that Influence Spontaneous Failure in Thermally Treated Glass-Nickel Sulphide, in Glass Processing Days. Tampere, Finland.

19. Wiederhorn S.M., Bolz L.H. (1970): Stress Corrosion and Static Fatigue of Glass. Journal of the American Ceramic Society, 53(10), 543-548. doi:10.1111/j.1151-2916.1970. tb15962.x

20. Ciccotti M. (2009): Stress-corrosion mechanisms in silicate glasses. Journal of Physics D: Applied Physics, 42(21), 214006. doi:10.1088/0022-3727/42/21/214006

21. Gy R. (2003): Stress corrosion of silicate glass: a review. Journal of Non-Crystalline Solids, 316(1), 1-11. doi:10.1016/S0022-3093(02)01931-2

22. Griffith A.A. (1921): The Phenomena of Rupture and Flow in Solids. Philosophical Transactions of the Royal Society of London - Series A, Containing Papers of a Mathematical or Physical Character, 221, 163-198.

23. Haldimann M., Luible A., Overend M. (2008). Structural use of Glass, in: Vol. 10. Structural Engineering Documents.

24. Gelderie U., Kasper A. (2008): How to prevent spontaneous breakage of thermally toughened alkaline earth silicate glass. Glass Technology - European Journal of Glass Science and Technology Part A, 49(3), 126-132.

25. Molnár G., Bojtár I. (2013): Effects of Manufacturing Inhomogeneities on Strength Properties of Float Glass. Mechanics of Materials, 59(0), 1-13. doi: 10.1016/j. mechmat.2012.11.012

26. Johnson R.R. (2008): Managing the Problems Inherent in Tempered Glass. US Glass Magazine, 43(6).

27. Weko A.G. (2016). Spontaneous Breakage, in: Glass on Web.

28. Ballantyne E. (1961). Fracture of Toughened Glass Wall Cladding. ICI House, Commonwealth Scientific and Industrial Research Organization, Division of Building Research.

29. Jacob L. (2001). A Review of the Nickel Sulphide Induced Fracture in Tempered Glass. in: Glass Performance Days. Tampere, Finland.

30. Jacob L., Calderone I. (2003). Nickel Sulphide Inclusions - Important Issues for the Designer. In: Glass Performance Days. Tampere, Finland.

31. Nash P. (1991). Phase diagrams of binary nickel alloys. in: ASM International, pp. 394.

32. Kullerud G., Yund R.A. (1962): The Ni-S System and Related Minerals. Journal of Petrology, 3(1), 126-175. doi:10.1093/petrology/3.1.126

33. Wagner R. (1977): Nickelsulfid-Einschlüsse in Glas. Glastechnische Berichte, 11, 296.

34. Fleet M.E. (1988): Stoichiometry, structure and twinning of godlevskite and synthetic low-temperature Ni-excess nickel sulfide. Canadian Mineralogist, 26, 283-291.

35. Swain M.V. (1981): Nickel sulphide inclusions in glass: an example of microcracking induced by a volumetric expanding phase change. Journal of Materials Science, 16(1), 151-158. doi:10.1007/bf00552069.

36. Hsiao C. (1977). Spontaneous fracture of tempered glass, in: ICF4, Waterloo, Canada.
37. Bao Y., Liu L., Han S., Shi X., Yang J. (2007): A new mechanism of spontaneous breakage of tempered glassmonolithic silicon particles. Journal of the Chinese Ceramic Society, 35(9). 1273.

38. Bao Y., Yang J., Qiu Y., Song Y. (2009): Space and time effects of stress on cracking of glass. Materials Science and Engineering: A, 512(1-2), 45-52. doi:10.1016/j. msea.2009.01.071

39. Kasper A., Stadelmann H. (2002): Chemical behavior of nickel sulfide in soda-lime-silica glass melts. Glass science and technology, 75(1), 1-11.

40. Wasylak J., Reben M., Bielecki S. (2011): Behaviour of nickel sulphide inclusions in glass melts. Materiaty Ceramiczne, 63(1), 48-53.

41. Technical Information (2011). Spontaneous Breakage of Tempered Glass, Pilkington North America Inc.

42. Barry J.C., Ford S. (2001): An electron microscopic study of nickel sulfide inclusions in toughened glass. Journal of Materials Science, 36(15), 3721-3730. doi:10.1023/ a:1017921732763

43. Kasper A. (2000). Stability of nickel sulfide stones in glass melts. Glass science and technology, 73, 341-351.

44. Brungs M., Sugeng X. (1995): Some solutions to the nickel sulphide problem in toughened glass. Glass Technology, 36(4), 107-110.

45. Ostwald W. (1897): Studien über die Bildung und Umwandlung fester Körper. Zeitschrift für Physikalische Chemie, 22, 289-330.

46. Swain M.V. (1980): A fracture mechanics description of the microcracking about NiS inclusions in glass. Journal of Non-Crystalline Solids, 38, 451-456. doi:10.1016/00223093(80)90460-3

47. Mognato E., Barbieri A. (2013). The breakage of glass - Thermal shock and nickel sulfide inclusion, in: COST Action TU0905 Mid-term Conference on Structural Glass. CRC Press. pp. 155-164. doi:10.1201/b14563-23

48. Kasper A. Yousfi O. (2009). Spontaneous Glass Breakage Caused by Nickel Sulphide (a review). In: Glass Performance Days $(G P D)$. Tampere, Finland.

49. Stachel D., Zangenberg F., Müller T.E. (2007): Chemical behaviour of metallic inclusions in glass melts. Journal of Physics and Chemistry of Solids, 68(5-6), 1017-1020. doi:10.1016/j.jpcs.2007.02.051

50. Bordeaux F. Kasper A. (1997). Reliable and shorter heat soak test to avoid spontaneous fracture of heat strengthened and tempered glasses. In: Glass Processing Days. Tampere, Finland.

51. Gelder D. (2001). The Significance of Sub-critical NiS Inclusions, in: Glass Performance Days. Tampere, Finland.

52. Bowler-Reed J. (2002). The Disintegration of Thermally Toughened Glass by Nickel Sulphide Inclusions. In: Glass Technology: Glass and Glazing Products. pp. 67-69.

53. Bishop D.W., Thomas P.S., Ray A.S. (1999): $\alpha-\beta$ Phase Re-Transformation Kinetics in Nickel Sulphide. Journal of Thermal Analysis and Calorimetry, 56(1), 429-435. doi:10.1023/a:1010179424043

54. Bishop D.W., Thomas P.S., Ray A.S., Šimon P. (2001): Two-Stage Kinetic Model for the $\alpha-\beta$ Phase Recrystallisation in Nickel Sulphide. Journal of Thermal Analysis and Calorimetry, 64(1), 201-210. doi:10.1023/ a: 1011597315456

55. Yousfi O., Bréchet Y.J., Donnadieu P., Robaut F., Charlot 
F., Kasper A., aSerruys F. (2011). Phase Transformations in the NiS Nickel Sulphide: Microstructure, Mechanisms and Modelling through In Situ Microscopy, In: Solid State Phenomena. Trans Tech Publ.

56. Yousfi O., Donnadieu P., Bréchet Y., Robaut F., Charlot F., Kasper A., Serruys, F. (2010): Phase transformations in nickel sulphide: Microstructures and mechanisms. Acta Materialia, 58(9), 3367-3380. doi:10.1016/j.actamat. 2010.02.011

57. Rajamani V.T., Prewitt C. (1974): The crystal structure of millerite. The Canadian Mineralogist, 12(4), 253-257. doi:10.1021/cm7033883

58. Greenwood N.N.,Earnshaw A. (2012). Chemistry of the Elements. Elsevier.

59. Grice J.,Ferguson R. (1974): Crystal structure refinement of millerite (beta-NiS). The Canadian Mineralogist, 12(4), 248-252.

60. Schneider J., Hilcken J., Kasper A. (2012): Ein Modell zur Bestimmung der Versagenswahrscheinlichkeit von heißgelagertem ESG. Stahlbau, 81(S1), 171-184. doi:10.1002/ stab.201290061

61. Merker L. (1974): Zum Verhalten des Nickelsulfids im Glas. Glastechnische Berichte, 47(6), 116-121

62. Kim B., Chou C.C., Wayman C.M. (1992). The alpha to beta transformation in stoichiometric NiS. in Proc. Int. Conf. on Martensitic Transformations. Monterey, CF, USA.

63. Schneider J., Hilcken J. (2010). Nickel Sulphide (NiS-) induced failure of glass: fracture mechanics model and verification by fracture data. in Engineered Transparency. Düsseldorf, Germany.

64. Barry J. (2006). The Achilles Heel of a Wonderful Material: Toughened Glass, in: Glass on Web.

65. Yi-Wang B., Zheng-Quan L. (2016): Mechanism and Criterion of Spontaneous Breakage of Tempered Glass. Journal of Inorganic Materials, 31(4), 401-406. doi:10.15541/jim20150444

66. Barry J.C. (1993): A study of nickel sulphide stones in tempered glass. Ultramicroscopy, 52(3), 297-305. doi:10.1016/0304-3991(93)90039-Z

67. Gromovski K. (2010). Glass Breakage - Nickel Sulfide Inclusions. Pennsylvania State University.

68. Tölke T., Barz A., Stachel D. (2007): Behaviour and phase transformations of nickel sulphide inclusions in glass melts. Journal of Physics and Chemistry of Solids, 68(5-6), 830-834. doi:10.1016/j.jpcs.2007.03.042

69. Tabuchi H. (1974). On the study of sulfide inclusions in plate glasses. In: International Congress on Glass. Kyoto, Japan.

70. Kasper A., Bordeaux F., Duffrene L. (2000): Nickel sulphide: new results to optimise the heat soak test for thermally toughened building glasses. Glass science and technology, 73(5), 130-142.

71. Thomas P.S., Šimon P., Ray A.S. (2003): The effect of Thermal History on the Morphology of Nickel sulphide. Journal of Thermal Analysis and Calorimetry, 72(3), 801809. doi:10.1023/a:1025057929548

72. Christian J.W. (2002). The theory of transformations in metals and alloys. Part 1. $3^{\text {rd }}$ ed. Elsevier Science Ltd.

73. Yousfi O. (2009). Transformations de phase des Sulfures de Nickel dans les verres trempés, Doctoral Thesis. Institut polytechnique de Grenoble.

74. Wang H., Pring A., Ngothai Y., O'neill B. (2006): The kinetics of the $\alpha \rightarrow \beta$ transition in synthetic nickel monosulphide. American Mineralogist, 91(1), 171-181. doi:10.2138/am.2006.1962

75. Krishnakumar S.R., Shanthi N., Sarma D.D. (2002): Electronic structure of millerite NiS. Physical Review B, 66(11), 115105. doi:10.1103/PhysRevB.66.115105

76. http://napierblakeley.info/maintenance/the-shatteringtruth-about-glass/.(2010) [Accessed 2016-09-20].

77. Jin Y., Wang Z., Zhu L., Yang J. (2011): Research on in-line glass defect inspection technology based on Dual CCFL. Procedia Engineering, 15, 1797-1801. doi:10.1016/j. proeng.2011.08.334

78. Reeves J. (2004). Nickel Sulphide inclusions - A report on the phenomena of spontaneous breakage in fully tempered glass. Gulf Glass Industries U.A.E.

79. Malou Z., Hamidouche M., Bouaouadja N., Chevalier J., Fantozzi G. (2013) : Thermal Shock Resistance of Soda Lime Glass. Ceramics-Silikáty, 57(1), 39-44.

80. Bradt R.C. (2011). The Fractography and Crack Patterns of Broken Glass. Journal of Failure Analysis and Prevention, 11(2): p. 79-96. doi:10.1007/s11668-011-9432-5

81. Choi S.R., Gyekenyesi J.P. (1998). Crack branching and fracture mirror data of glasses and advanced ceramics, in: NASA/TM-1998-206536.

82. Bansal G.K. (1977): On fracture mirror formation in glass and polycrystalline ceramics. Philosophical Magazine, 35(4), 935-944. doi:10.1080/14786437708232635

83. Quinn J.B. (1999): Extrapolation of Fracture Mirror and Crack-Branch Sizes to Large Dimensions in Biaxial Strength Tests of Glass. Journal of the American Ceramic Society, 82(8), 2126-2132. doi:10.1111/j.1151-2916.1999. tb02052.x

84. Vigener N., Brown M. (2009). Building Envelope Design Guide-Glazing, in: Whole Building Design Guide, National Institute of Building Science.

85. Kasper A. (2003). Spontaneous Cracking of Thermally Toughened Safety Glass: Actual State of Discussion in Research and Practice. in Advances in Fusion and Processing of Glass III. Rochester, New York, United States. doi:10.1002/9781118405949.ch47

86. Kasper A. (2002). Heat Soaking Avoids Spontaneous Cracking of Thermally Toughened Safety Glass, In: GlassTech, Asia.

87. Kasper A. (2003). Nickelsulfid in Glas, Fortschritt. Verlag der Deutschen Glastechnischen Gesellschaft.

88. Schaefer C., Bräuer G., Szczyrbowski J. (1997): Low emissivity coatings on architectural glass. Surface and Coatings Technology, 93(1), 37-45. doi:10.1016/S02578972(97)00034-0

89. Solinov V.F. (2007): Effect of nickel sulfide inclusions on the spontaneous failure of toughened glasses. Glass and Ceramics, 64(5), 149-152. doi:10.1007/s10717-0070038-z

90. Schneider J., Hilcken J., Aronen A., Karvinen R., Olesen J.F., Nielsen J. (2016): Stress relaxation in tempered glass caused by heat soak testing. Engineering Structures, 122, 42-49. doi:10.1016/j.engstruct.2016.04.024

91. Kasper, A. (2000): Nickel sulphide: supplementary statistical data of the heat soak test. Glass science and technology, 73(11), 356-359.

92. Kissinger H.E. (1956): Variation of peak temperature with heating rate in differential thermal analysis. Journal of Research of the National Bureau of Standards, 57(4), 217-221. 
93. Sakai C., Kikuta M. (1999). Adapted heat treatment for phase transformation of NiS inclusion in the heat strengthened and tempered glass, in: Glass Processing Days. Tampere, Finland.

94. Sakai C., Kikuta M. (2007). Heat soak test (HST) with high reliability, in: Glass Performance Days. Tampere, Finland.

95. Yousfi O., Brechet Y., Donnadieu P., Kasper A., Serruys F. (2009). Proposal to enhance the heat soak test following EN-14179-1, in: Glass Performance Days. Tampere, Finland

96. Ray A., Jacob L. (2006): Glass breaks from nickel sulfide inclusions. Glass Magazine, 56(10), 64-70. http://hdl. handle.net/10453/6090

97. Ford T.J. (1997). Spontaneous fracture of glass due to nickel sulfide inclusions: risk management and development of a non destructive testing system. in: Proceedings of International Conference on Building Envelope Systems and Technology (ICBEST), CWCT Services, Bath, UK.

98. Li X., Fang Z.P., Reading I., Zhao L., Chow S.L. (2005). In situ inspection of inclusions in toughened glass panels of high-rise buildings. in: Microtechnologies for the New Millennium 2005. International Society for Optics and Photonics. doi:10.1117/12.621451

99. Haller K., (2008). Acoustical measurements of material nonlinearity and nonequilibrium recovery, Doctoral Thesis. Department of Mechanical Engineering, Blekinge Institute of Technology.

100. Duquennoy M., Devos D., Ouaftouh M., Lochegnies D., Roméro E. (2006): Ultrasonic evaluation of residual stresses in flat glass tempering: Comparing experimental investigation and numerical modeling. The Journal of the Acoustical Society of America, 119(6), 3773-3781. doi:10.1121/1.2197806

101.Kushibiki J.-I., Arakawa M., Ohashi Y., Kawaguchi K., Takeda N. (2013). Ultrasonic Microspectroscopy of Tempered Glasses. in Proceedings of Symposium on Ultrasonic Electronics.

102. Arakawa M., Kushibiki J.-I., Kawaguchi K., Takeda N., Ohashi Y. (2014). A novel method of evaluating surface properties of tempered glasses by the ultrasonic microspectroscopy technology. in: Ultrasonics Symposium (IUS), 2014 IEEE International. doi:10.1109/ultsym. 2014.0344

103. Aben H., Anton J., Errapart A. (2008): Modern Photoelasticity for Residual Stress Measurement in Glass. Strain, 44(1), 40-48. doi:10.1111/j.1475-1305.2008.00422.x

104. Hödemann S., Valdmann A., Anton J., Murata T. (2016): Gradient scattered light method for non-destructive stress profile determination in chemically strengthened glass. Journal of Materials Science, 51(12), 1-17. doi:10.1007/ s10853-016-9897-4

105.Li X., Fang Z.P., Ng F.L., Zhao L.P., Zhao L. (2006). Inspection and Image Analysis of Nickel Sulphide Inclusions in Toughened Glass Panels. in: $20069^{\text {th }}$ International Conference on Control, Automation, Robotics and Vision. doi:10.1109/ICARCV.2006.345068

106. Jensen M., Keding R., Yue Y. (2010): Quantification of Chemical Striae in Inorganic Melts and Glasses through Picture Processing. Journal of the American
Ceramic Society, 93(9), 2705-2712. doi:10.1111/j.15512916.2010.03784.x

107. Nielsen K.H., Karlsson S., Limbach R., Wondraczek L. (2015): Quantitative image analysis for evaluating the abrasion resistance of nanoporous silica films on glass. Scientific Reports, 5, 17708. doi:10.1038/srep17708

108. Hotar V., Novotny F., Reinischova H. (2011): Objective evaluation of the corrugation test for sheet glass surfaces. Glass Technology - European Journal of Glass Science and Technology Part A, 52(6), 197-202

109. Sobhani A., Salavati-Niasari M. (2013): Synthesis, characterization, optical and magnetic properties of a nickel sulfide series by three different methods. Superlattices and Microstructures, 59, 1-12. doi:10.1016/j.spmi.2013. 03.018

110. Bishop D.W., Thomas P.S., Ray A.S. (2000): Micro Raman characterization of nickel sulfide inclusions in toughened glass. Materials Research Bulletin, 35(7), 1123-1128. doi:10.1016/S0025-5408(00)00296-8

111. Sehgal J., Ito S. (1998): A New Low-Brittleness Glass in the Soda-Lime-Silica Glass Family. Journal of the American Ceramic Society, 81(9), 2485-2488. doi:10.1111/j.11512916.1998.tb02649.x

112. Rouxel T., Sellappan P., Célarié F., Houizot P., Sanglebœuf J.-C. (2014): Toward glasses with better indentation cracking resistance. Comptes Rendus Mécanique, 342(1), 46-51. doi:10.1016/j.crme.2013.10.008

113. Rouxel T. (2015): Driving force for indentation cracking in glass: composition, pressure and temperature dependence. Philosophical Transactions of the Royal Society of London A: Mathematical, Physical and Engineering Sciences, 373(2038), 1-26. doi:10.1098/rsta.2014.0140

114. Allsopp B., Orman R., Johnson S.R., Baistow I., Lundstedt K., Sundberg P., Baquedano-Peralvarez E., Stålhandske C., Andersson A., Postigo P.A., Booth J., Bingham P.A., Karlsson S. (2016). Towards Ultra-Thin Glasses for Solar Energy Applications, in: EU PVSEC, Munich, Germany.

115. Wondraczek L., Mauro J.C., Eckert J., Kühn U., Horbach J., Deubener J., Rouxel T. (2011): Towards Ultrastrong Glasses. Advanced Materials, 23(39), 4578-4586. doi:10.1002/adma.201102795

116. Gy R. (2008): Ion exchange for glass strengthening. Materials science \& engineering. B, Solid-state materials for advanced technology, 149(2), 159. doi: 10.1016/j. mseb.2007.11.029

117. Varshneya A.K. (2010): The Physics of Chemical Strengthening of Glass: Room for a New View. Journal of Non-Crystalline Solids, 356(44-49), 2289-2294. doi:10.1016/j.jnoncrysol.2010.05.010

118. Varshneya A.K. (2010): Chemical Strengthening of Glass: Lessons Learned and Yet To Be Learned. International Journal of Applied Glass Science, 1(2), 131-142. doi:10.1111/j.2041-1294.2010.00010.x

119. Bishop D.W., Thomas P.S., Ray A.S. (1998): Raman spectra of nickel(II) sulfide. Materials Research Bulletin, 33(9), 1303-1306. doi:10.1016/S0025-5408(98)00121-4 